\title{
Key questions to ask patients who are veterans
}

\author{
David C. Fipps, DO, and Elisabet Rainey, MD
}

Dr. Fipps is a Consultation-Liaison Psychiatry Fellow, Mayo Clinic, Rochester, Minnesota. Dr. Rainey is a Veteran's Administration Psychiatrist, Greenville VA Outpatient Clinic, Greenville, South Carolina.

\section{Disclosures}

The authors report no financial relationships with any companies whose products are mentioned in this article, or with manufacturers of competing products.

doi: $10.12788 /$ cp.0082

\section{f}

Discuss this article at www.facebook.com/ MDedgePsychiatry
T he Mission Act-signed into law in 2018-recognizes that the health care needs of patients who are veterans can no longer be fully served by the Veterans Health Administration. ${ }^{1}$ This act allows some veterans who are enrolled in the Veterans Affairs (VA) health care system or otherwise entitled to VA care to access treatment outside of VA facilities. ${ }^{1}$ As a result, psychiatrists may treat veterans more frequently.

During such patients' initial visit, obtaining a detailed history of their military service can reveal vital clinical information and establish a therapeutic alliance that can help foster positive treatment outcomes. Here we offer an A-to-L list of important questions to ask veterans about their military service, and explanations of why these questions are valuable.

Attained rank. What rank did you attain during your military service? Did you retire from the military? How many years did you serve?

Asking about your patient's rank, retirement status, and time in service is vital to understanding their military experience. By military law, only individuals who retired from the military can use their rank as an identifier after they leave the military, although some veterans may not wish to be called by their rank in a clinical setting.

Branch. Which branch of the military did you serve? Were you in Active Duty, the Reserves, or the National Guard?

Military members often take great pride in service of their specific branch. Each branch has its own language, culture, val- ues, and exposures. If your patient has served in a combination of Active Duty, Reserves, and/or National Guard, ask how much time they spent in each.

Culture. What part of the military culture was positive or negative for you?

There is a clear culture within the military. Some veterans may feel lost without the military structure, and even devalued without the respect of rank. Others may feel jaded and spiteful about the strict military culture, procedures, and expectations.

Discharge. When, why, and under what circumstances were you discharged? What type of discharge did you receive?

There are 6 types of discharge: Honorable, General, Other than Honorable (OTH), Entry Level Separation, Bad Conduct, and Dishonorable. The type of discharge a veteran received may impact what resources are available to them. It also can influence a veteran's perception of their military career.

Exposures. Were you exposed to combat, death, explosive blasts, or hazardous chemicals?

\section{Every issue of CURRent PsyChIATRY} has its 'Pearls'

\section{Yours could be found here.}

Read the 'Pearls' guidelines for manuscript submission at MDedge.com/ CurrentPsychiatry/page/pearls. Then, share with your peers a 'Pearl' of wisdom from your practice. 
Do not ask a veteran if they have killed anyone. This question is both disrespectful and highly presumptuous because most veterans have not killed anyone. Be respectful of their experiences. Depending on the veteran's mission, they may have unique exposures (Agent Orange, burn pits, detainee camps, etc.). Consider asking follow-up questions to learn the details of these exposures.

Family impact. How has your military service impacted your family?

A veteran's military service often affects family members. Deployments can cause strain on marital relationships, children's birthdays and special events may be missed, and extended family may have negative reactions to military service. Understanding the impact on the veteran's family members can help uncover potential stressful relationships as well as help enhance any positive support systems that are available at home.

Go. Where were you stationed? Were you deployed?

Training location, geography of combat theater, peace-keeping locations, and area of station can all profoundly impact a veteran's military experience. Ask followup questions about their duty stations, deployment locations, and experiences with these locations.

Hot water. Did you ever get into "trouble" while serving the military (eg, lose rank, get arrested, etc.)? How did you respond to the military's method of discipline?

Although it may be difficult or uncomfortable to ask your patient if they experienced any disciplinary action, this information may prove useful. It can help provide context when you discuss the veteran's ease of assimilation into civilian life and other important information regarding the type of discharge.
Injuries. Have you experienced any moral, physical, sexual, emotional, or concussive injuries?

Moral injury, guilt, and regret are common for veterans. Not all injuries are from combat. Your patient may have experienced sexual assault, hazing rituals, pranks, etc.

Job. What was your job in the military? What kind of security clearance did you have?

Note that not all veterans' "jobs" in the military accurately reflect the duties and tasks that they actually performed. Security clearance will often influence the duties and tasks they were required to perform.

Keeping it inside. Do you have anyone to talk with about your military experiences?

Many veterans feel uncomfortable discussing their experiences with others. Some veterans may be concerned that others will not understand what they went through. Some might perceive that disclosing their experiences could burden other people, or they may be concerned that explaining their experiences may be too shocking. Asking this question may present an opportunity for you to suggest psychotherapy for your patient.

Life as a civilian. How is your life different as a civilian? How have you adjusted to civilian life?

During the process of assimilation into civilian life, veterans may experience symptoms of depression, posttraumatic stress disorder, anxiety, or other disorders. These symptoms may emerge and/or become exacerbated during their transition to civilian life.

\section{Reference}

1. VA MISSION Act of 2018 (VA Maintaining Internal Systems and Strengthening Integrated Outside Networks Act), S 2372, 115th Cong, 2nd Sess, HR Doc No. 115-671 (2018).

\section{Asking about a veteran patient's rank, retirement status, and time in service helps to understand their military experience}

